\title{
Endoscopic Endonasal Surgery of a Large Vidian Nerve Schwannoma With Preparation for Avoiding Major Vascular Injury
}

\author{
Chisato Tanaka $^{1}$, Masahiro Kikuchi ${ }^{2}$, Mami Matsunaga ${ }^{2}$, Koichi Omori ${ }^{2}$, Takayuki Nakagawa ${ }^{2}$ \\ 1. Otolaryngology, Head and Neck Surgery, Osaka Red Cross Hospital, Osaka, JPN 2. Otolaryngology, Head and Neck \\ Surgery, Graduate School of Medicine, Kyoto University, Kyoto, JPN
}

Corresponding author: Masahiro Kikuchi, m_kikuchi@ent.kuhp.kyoto-u.ac.jp

\begin{abstract}
Vidian nerve schwannomas are extremely rare, and their surgical management requires an awareness of the surrounding vascular and nervous systems, including the internal carotid artery. Herein, we report a case of a vidian nerve schwannoma that was successfully removed using an endoscopic endonasal approach in a 21 year-old patient who presented with lacrimal hyposecretion. Imaging revealed a large mass extending to the middle cranial fossa posteriorly, to the pterygopalatine fossa laterally, and to the sphenoid sinus medially. The paraclival and petrosal portions of the internal carotid artery were displaced posteriorly. Endoscopic observation of the right nose demonstrated anterior displacement of the inferior portion of the middle turbinate. Based on the above, we suspected a vidian nerve schwannoma, and endoscopic endonasal surgery was performed with particular attention to avoid vascular injuries. An endoscopic transmaxillary approach was used to expose the anterior surface of the tumor. After confirming the pathological diagnosis intraoperatively, intracapsular resection of the tumor was completed using an ultrasonic surgical aspirator with Doppler monitoring of the location of the internal carotid artery. Endoscopic management of the surgical field and preparation to avoid vascular injury are essential for safe and efficient tumor resection.
\end{abstract}

Review began 03/26/2021 Review ended 03/30/2021 Published 03/31/2021

(c) Copyright 2021 Tanaka et al. This is an open access article distributed under the terms of the Creative Commons Attribution License CC-BY 4.0., which permits unrestricted use, distribution, and reproduction in any medium, provided the original author and source are credited.
Categories: Otolaryngology

Keywords: vidian nerve, schwannoma, endoscopic endonasal surgery, ultrasonic surgical aspirator, surgical navigation system

\section{Introduction}

The vidian nerve consists of sympathetic fibers originating from the deep petrosal nerve and parasympathetic fibers from the greater petrosal nerve which innervates the lacrimal gland and the nasopalatine mucosa. This nerve exits the cranial cavity anterior to the horizontal segment of the petrous internal carotid artery (ICA), courses anteriorly through the pterygoid canal, and exits the skull base through the foramen on the face of the pterygoid plates within the pterygopalatine fossa [1]. Therefore, the vidian nerve has emerged as a surgical landmark for the foramen lacerum and second genu of the ICA during endoscopic endonasal skull base surgery [2].

Schwannomas are benign tumors of the Schwann cells that coat the nerve sheath. Vestibular nerve schwannomas are the most common, followed by trigeminal nerve schwannomas [3]. Vidian nerve schwannomas are extremely rare. Herein, we present a case of a large vidian nerve schwannoma primarily manifesting with lacrimal hyposecretion that was successfully treated with endoscopic endonasal surgery.

\section{Case Presentation}

A previously healthy 21-year-old woman was referred to our hospital with an incidental finding of a right middle cranial fossa tumor measuring $44 \mathrm{~mm}$ in maximum diameter on computed tomography (CT) imaging performed for head injury. The patient had a six-year history of dryness affecting her right eye but without visual symptoms, nasal symptoms, or facial numbness.

The Schirmer's test was performed to assess tear secretion; the results were $6 \mathrm{~mm}$ on the right and $24 \mathrm{~mm}$ on the left, indicating decreased tear production on the right side. Nasal endoscopy showed anterior displacement of the posteroinferior part of the middle turbinate, but we were unable to visualize the tumor. Therefore, the patient underwent contrast-enhanced CT imaging, which revealed a slightly enhanced expansile soft tissue mass that occupied the floor of the sphenoid sinus and displaced the pterygopalatine fossa anteriorly on the right side with no bony invasion. The foramen rotundum, vidian canal, and foramen lacerum on the right side were not detected (Figure 1). 


\section{Cureus}

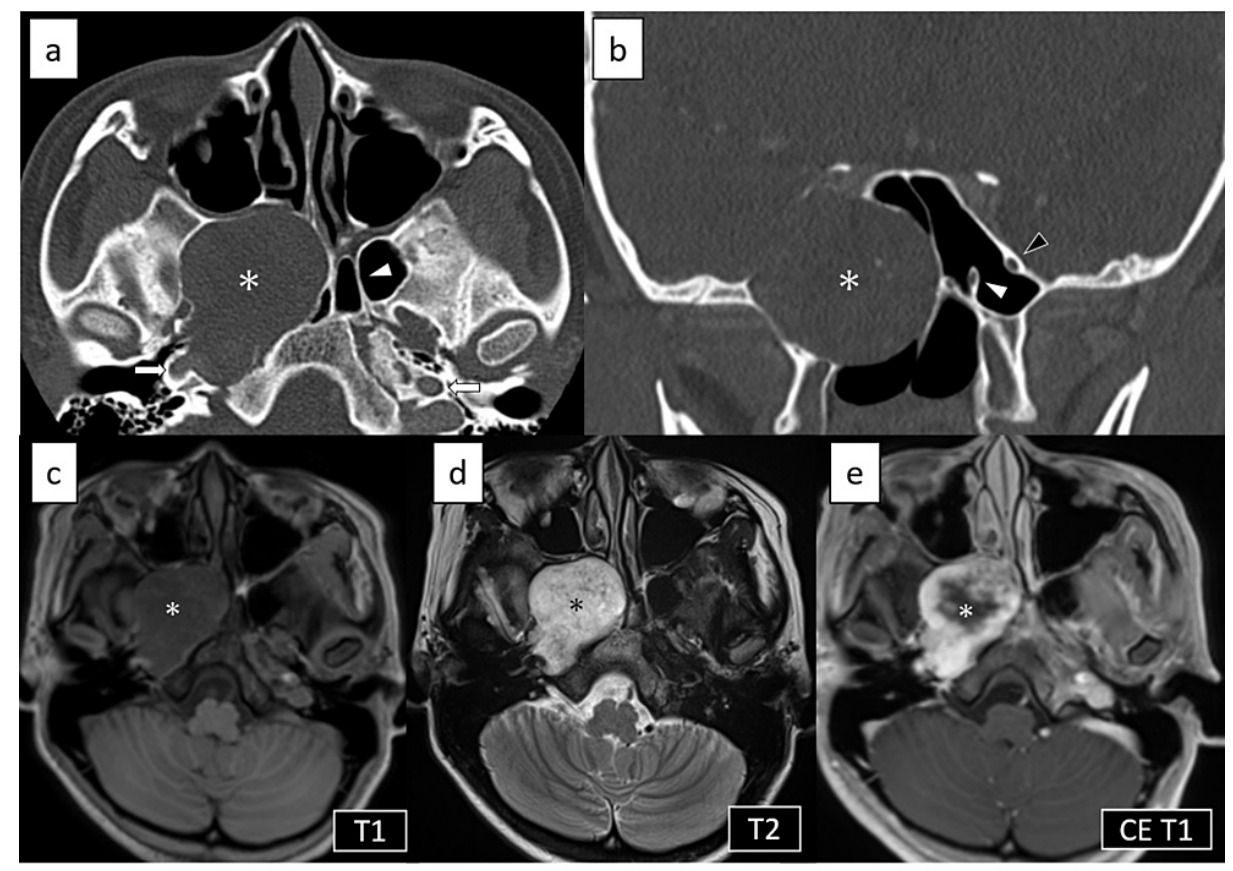

\section{FIGURE 1: Preoperative CT and MRI}

The tumor occupied the floor of the sphenoid sinus and displaced the pterygopalatine fossa anteriorly on the right side (asterisk). a) Axial plain $\mathrm{CT}$ image. Vidian canal and foramen lacerum on the right side were not detected. White arrowhead: left vidian canal. White arrows: carotid canals. b) Coronal plain CT image. The surrounding bone was thinned, but no bony invasion was present. We were able to identify the vidian canal and foramen rotundum on the left side but not on the right side. White arrowhead: left vidian canal. Black arrowhead: left foramen rotundum. On MRI, the tumor was (c) low signal on T1-weighted image, (d) high signal on T2-weighted image, and (e) slightly and heterogeneously enhanced.

On magnetic resonance imaging (MRI), the tumor had low signal intensity on T1-weighted images and high signal intensity on T2-weighted images, with slight and heterogeneous gadolinium enhancement (Figure 1). The course of the ICA was thoroughly evaluated using MRI and magnetic resonance angiography (MRA). MRI with the DANTE-SPACE sequence revealed that the paraclival and petrous portion of the right ICA were in contact with the tumor posteriorly, and its course was postero-laterally displaced by the tumor (Figure 2). Preoperative virtual images from MRA and MRI using the surgical navigation system (StealthStation ${ }^{\mathrm{TM}}$ ENT Navigation System, Medtronic, Minneapolis, MN, USA) were obtained in advance to evaluate the relationship between the tumor and the course of the adjacent ICA (Figure 2). 


\section{Cureus}

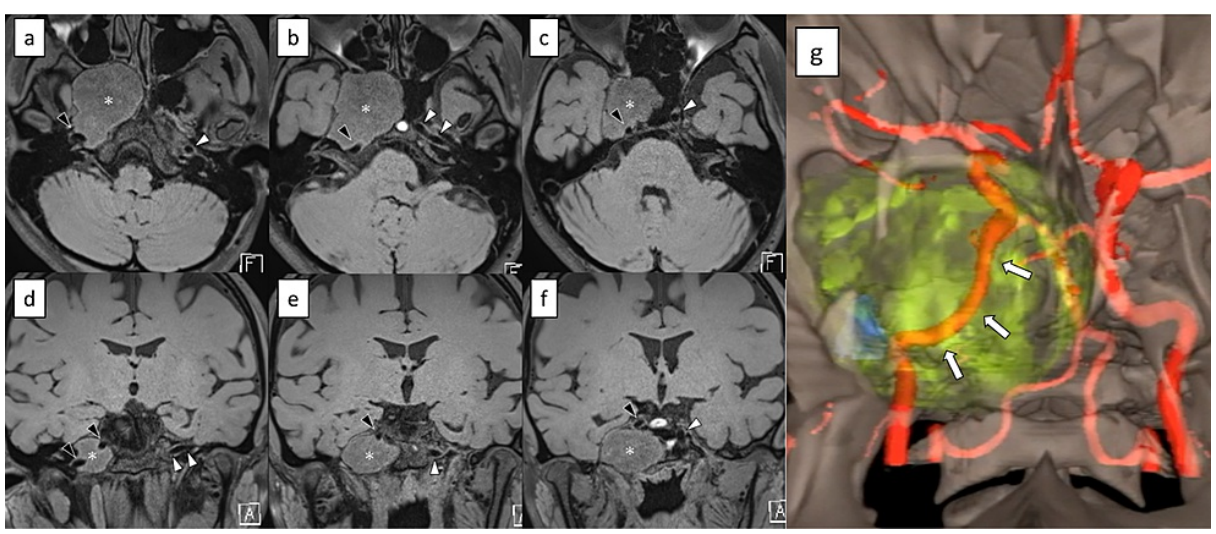

FIGURE 2: Preoperative assessment of the course of the internal carotid artery

(a-f) Non-contrast MRI with DANTE-SPACE sequence. a) to c) are axial images (caudal to cephalad). d) to f) are coronal images (posterior to anterior). The internal carotid artery behind the tumor was appreciated by black blood image. g) Virtual image made from MRA and MRI using the surgical navigation system. Red: artery; yellow: tumor; blue: foramen ovale. The paraclival and petrous portion of the internal carotid artery on the right side was postero-laterally displaced by the tumor (arrows). Asterisk: tumor. Black arrowhead: internal carotid artery on the right side. White arrowhead: internal carotid artery on the left side.

Based on imaging findings, the differential diagnoses were neurogenic tumor of vidian nerve (such as schwannoma and neurofibroma), chordoma or juvenile angiofibroma. However, juvenile angiofibroma was less likely due to the mild contrast effects on CT and MRI. Therefore, we suspected a neurogenic tumor of vidian nerve, which correlated with the patient's clinical symptoms. However, as we were unable to visualize the tumor surface in the nasal cavity, preoperative biopsy was not possible, and the patient provided consent for surgery.

First, right endoscopic modified medial maxillectomy (EMMM) was performed to access the posterior wall of the maxillary sinus while preserving the nasolacrimal duct [4]. To secure a wide surgical field, the posterior base of the right inferior turbinate was dissected and retracted anteriorly, and the lower half of the right middle turbinate was resected and removed. The inferior turbinate was preserved and repositioned after completion of the surgery. During dissection of the posterior end of the middle turbinate, there was active bleeding from a branch of the sphenopalatine artery, which was cauterized with bipolar cautery. After removing the posterior wall of the maxillary sinus, the right descending palatine artery and the sphenopalatine artery were cauterized and transected by bipolar cautery, and the proximal maxillary artery was ligated with endoscopic liga-clips and transected. Then, the contents of the pterygopalatine fossa were retracted laterally to expose the tumor capsule. The capsule was resected and a small sample was obtained for frozen section, which confirmed a diagnosis of schwannoma.

After harvesting the pedicled nasal septal mucosal flap on the left side, ala of the vomer, and posterior part of the perpendicular plate of the ethmoid bone, both sides of the anterior walls of the sphenoid bone were removed to make a sufficient corridor for bi-nostril 2-surgeon/3- or 4-handed technique in case of active bleeding. Thereafter, intracapsular piecemeal tumor resection was started with a surgical navigation system following the course of the ICA in order to avoid major vascular injury. After the tumor was surgically decompressed, the residual tumor was crushed and aspirated using an ultrasonic surgical aspirator. Macroscopically, the tumor was highly vascular and bled during the resection. A Doppler ultrasound was used to identify the surrounding ICA intraoperatively. When the tumor was completely removed except for the capsule, the paraclival ICA was finally exposed (Figure 3), but no active bleeding or cerebrospinal fluid leak was observed. The exposed ICA was covered with a pedicled nasal septum flap, which was harvested from the left side in advance to prevent the possibility of a fatal rupture in the future. During the operation, the foramen lacerum and the pterygoid canal artery and nerve could not be visualized. 


\section{Cureus}

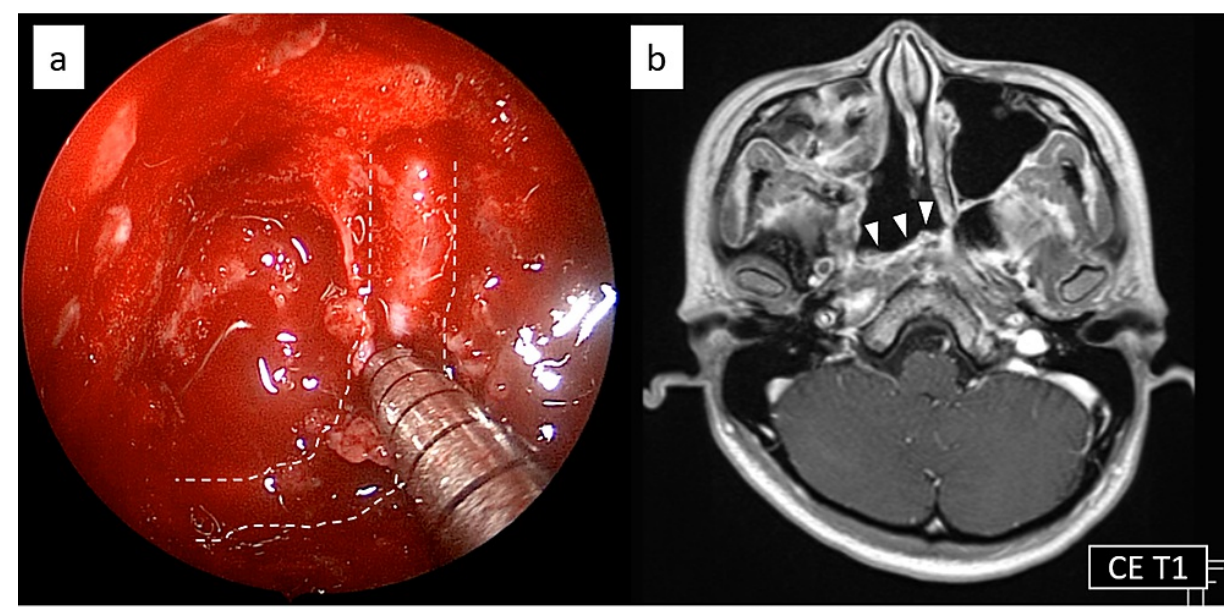

\section{FIGURE 3: Intraoperative image and postoperative MRI}

a) Endoscopic image at the end of the surgery. The paraclival portion of the internal carotid artery was exposed. White dotted line shows the course of the internal carotid artery. b) Contrast-enhanced MRI five months after the surgery showed no apparent recurrence. White arrow heads: the pedicled nasal septum flap covering the exposed internal carotid artery.

The patient's postoperative course was uneventful, with no bleeding or cerebrospinal fluid leaks, and she did not require a blood transfusion. She reported no change in cheek sensation and no worsening of right eye dryness. We did not insert gauze, but packed absorbable hemostat into the nose. Nasal irrigation with saline solution was started five days after the surgery and the patient was discharged from the hospital 15 days after the surgery. Post-operative MRI performed five months after the surgery showed no apparent tumor recurrence (Figure 3). Endoscopic image 11 months after surgery was shown in Figure 4.

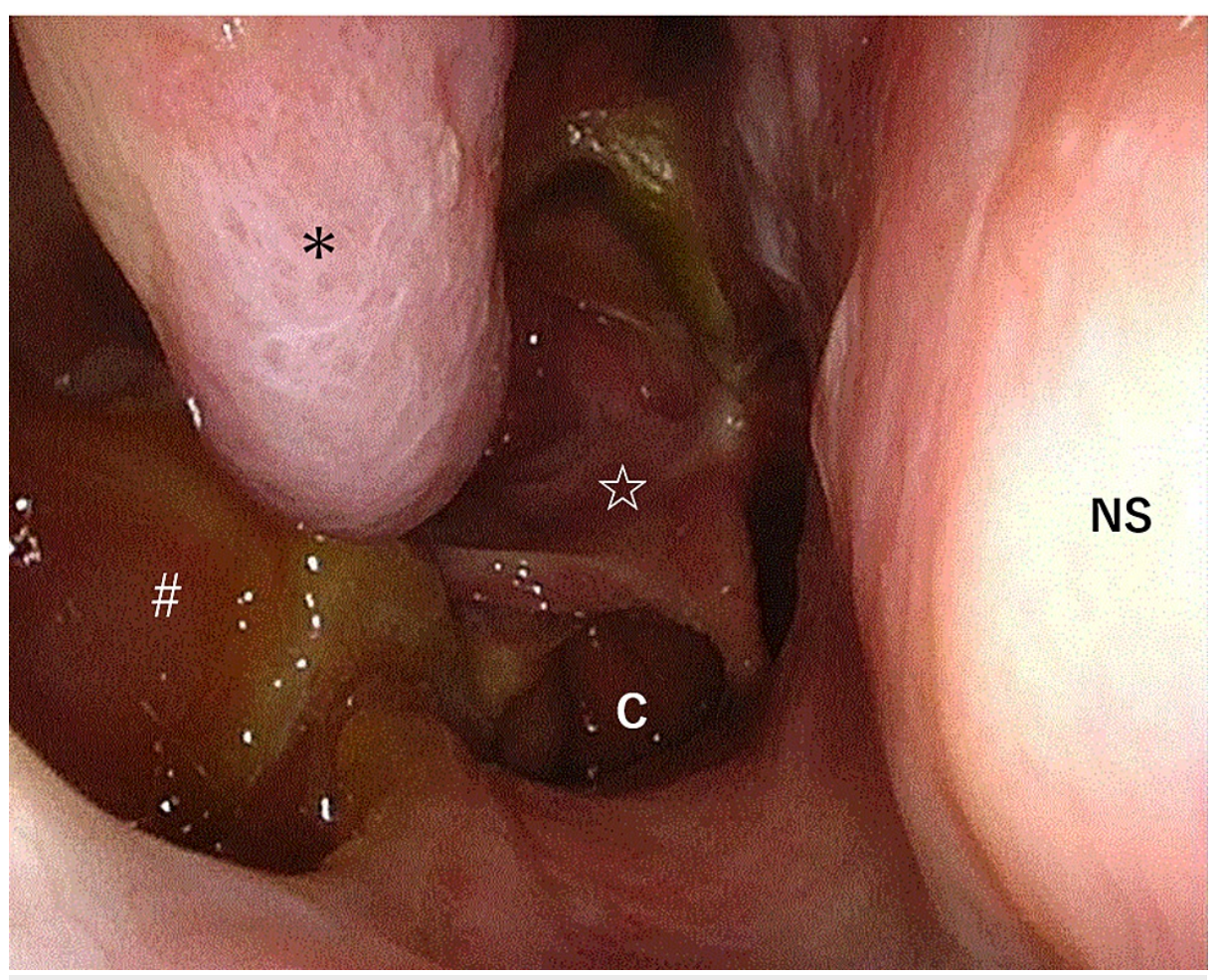

FIGURE 4: Endoscopic image 11 months after surgery.

Preserved inferior turbinate (*), opened pterygopalatine fossa (\#) on the right side and pedicled nasal septum flap harvested from the left side ( $)$ can be identified. NS: nasal septum, C: choana.

On histological examination, the tumor was composed of spindle cells with comma-like nuclei. Secondary degenerative changes, including hyalinization, hemorrhage, and calcification, were observed. These 
findings confirmed the diagnosis of a schwannoma.

Although we did not observe the pterygoid canal during the surgery, and therefore could not confirm the continuity between the tumor and the vidian nerve, the patient's clinical presentation and postoperative findings indicated that the origin of the schwannoma was the vidian nerve on the right side.

\section{Discussion}

Head and neck are common sites for schwannomas, accounting for 25\%-45\% of all schwannomas. In contrast, vidian nerve schwannomas are extremely rare. To the best of our knowledge, only 10 such cases (including the current case) have been reported in the literature and their clinical features are summarized in Table $1[1,3,5-10]$.

\begin{tabular}{|c|c|c|c|c|c|c|c|}
\hline No & Author & Age & Sex & Presentation & $\begin{array}{l}\text { Tumor } \\
\text { size }\end{array}$ & Treatment & Outcomes \\
\hline 1 & $\begin{array}{l}\text { Cheong et al., } 2006 \\
{[5]}\end{array}$ & 13 & $\mathrm{~F}$ & $\begin{array}{l}\text { Headache with unilateral facial nerve } \\
\text { palsy }\end{array}$ & $\begin{array}{l}12 \mathrm{~mm} \times \\
10 \mathrm{~mm}\end{array}$ & EES & N.A. \\
\hline 2 & $\begin{array}{l}\text { Honda et al., } 2008 \\
\text { [6] }\end{array}$ & 49 & $\mathbf{F}$ & $\begin{array}{l}\text { Unilateral hearing loss with serous } \\
\text { otitis media }\end{array}$ & N.A. & $\begin{array}{l}\text { Maxillary swing with } \\
\text { endoscopic assistance }\end{array}$ & $\begin{array}{l}\text { No recurrence } \\
\text { (1 month) }\end{array}$ \\
\hline 3 & $\begin{array}{l}\text { Hackman et al., } \\
2011[1]\end{array}$ & 49 & M & Occipital headache & $\begin{array}{l}10 \mathrm{~mm} \times \\
14 \mathrm{~mm}\end{array}$ & Follow up & N.A. \\
\hline 4 & $\begin{array}{l}\text { Hackman et al., } \\
2011[1]\end{array}$ & 58 & M & $\begin{array}{l}\text { Unilateral palate pain and lip } \\
\text { numbness }\end{array}$ & N.A. & EES & N.A. \\
\hline 5 & Wu et al., 2012 [7] & 78 & $\mathrm{~F}$ & $\begin{array}{l}\text { Unilateral oculomotor palsy with CSF } \\
\text { leakage }\end{array}$ & N.A. & EES & $\begin{array}{l}\text { No recurrence } \\
\text { (24 months) }\end{array}$ \\
\hline 6 & Hong et al., 2014 [8] & 41 & M & Occipital headache & $\begin{array}{l}28 \mathrm{~mm} \times \\
16 \mathrm{~mm}\end{array}$ & EES & N.A. \\
\hline 7 & $\begin{array}{l}\text { Yamasaki et } \\
\text { al., } 2015 \text { [9] }\end{array}$ & 49 & $\mathrm{~F}$ & Asymptomatic & $\begin{array}{l}20 \mathrm{~mm} \times \\
14 \mathrm{~mm}\end{array}$ & Radiation therapy & N.A. \\
\hline 8 & $\begin{array}{l}\text { Fortes et al., } 2019 \\
\text { [3] }\end{array}$ & 60 & $\mathrm{~F}$ & Unilateral facial hypoesthesia & N.A. & EES & $\begin{array}{l}\text { No recurrence } \\
\text { ( } 3 \text { months) }\end{array}$ \\
\hline 9 & $\begin{array}{l}\text { Masroor et al., } 2018 \\
\text { [10] }\end{array}$ & 54 & $F$ & $\begin{array}{l}\text { Periorbital pressure, third cranial } \\
\text { nerve palsy, visual field defects }\end{array}$ & $\begin{array}{l}41 \mathrm{~mm} \times \\
36 \mathrm{~mm}\end{array}$ & EES & $\begin{array}{l}\text { No recurrence } \\
\text { (28 months) }\end{array}$ \\
\hline 10 & $\begin{array}{l}\text { Tanaka et al., } 2021 \\
\text { (current case) }\end{array}$ & 21 & $\mathrm{~F}$ & Lacrimal hyposecretion & $\begin{array}{l}44 \mathrm{~mm} \times \\
36 \mathrm{~mm}\end{array}$ & EES & $\begin{array}{l}\text { No recurrence } \\
\text { (5 months) }\end{array}$ \\
\hline
\end{tabular}

\section{TABLE 1: Characteristics of previous case reports}

EES: Endoscopic endonasal surgery; CSF: Cerebrospinal fluid; F: Female; M: Male; NA: Not available.

Clinically, the patient described in the current report presented with decreased lacrimation, which is consistent with the innervation of the lacrimal gland by the vidian nerve. Surprisingly, this is the first case to preoperatively present with symptoms of vidian nerve dysfunction.

Endoscopic endonasal surgery was the most common surgical approach for vidian nerve schwannomas (seven out of 10 cases including the current case) [1,3,5,7,8,10]. During endoscopic endonasal surgery for removing vidian nerve schwannoma, the operation field, which is usually called "corridor" by skull base surgeons, was created depending on the size and extent of the tumor, but it is usually difficult to resect tumors using the trans-sphenoidal approach alone. Most tumors reported in the literature were removed in a wide surgical field after unilateral or bilateral wide-sphenoidectomy combined with trans-maxillary or transethmoidal approaches. To the best of our knowledge, the tumor diameter in the current case is the largest reported to date. When performing an endoscopic endonasal resection of such a large tumor, management of intraoperative bleeding is important, and the preoperative assessment of the course of large vessels is necessary. In addition, the risk of postoperative rapture should also be considered in reconstruction at the end of the surgery. In the present case, invasive preoperative angiography was not performed. Instead, the course of the ICA was thoroughly evaluated to prevent fatal bleeding. The DANTE-SPACE sequence can provide complete blood suppression and black blood imaging, and MRI performed with this sequence is 
usually used for the assessment of the arterial vessel wall and plaques [11]. In the current case, this allowed us to clearly visualize the course of the ICA behind the tumor. Owing to the preoperative meticulous evaluation of the course of the ICA and the intraoperative use of Doppler ultrasound, we could safely remove the tumor around the ICA.

Intraoperative bleeding can be managed by packing gauze soaked with epinephrine or using bipolar cautery. When dissecting the middle turbinate, active bleeding was observed from a branch of the sphenopalatine artery. Although there were no complications caused by bleeding, on further consideration, we could have ligated the maxillary artery prior to resecting the middle turbinate as this may have reduced the amount of bleeding.

Compared to extracapsular resection, intracapsular resection is thought to be superior for the preservation of origin nerve function [12]. In this case, intracapsular piecemeal tumor resection was performed, and at the end of the surgery, the residual tumor was crushed and aspirated using an ultrasonic surgical device. Intracapsular tumor resection using an ultrasonic surgical device is thought to be safe and effective, especially for large tumors located near large vessels such as the ICA.

\section{Conclusions}

We report a case of endoscopic endonasal surgery for a vidian nerve schwannoma that had invaded the pterygopalatine fossa and middle cranial fossa. By using an intraoperative navigation system, Doppler ultrasound, and an ultrasonic surgical device, we were able to perform minimally invasive surgery with complete intracapsular resection of the tumor.

\section{Additional Information \\ Disclosures}

Human subjects: Consent was obtained or waived by all participants in this study. Kyoto University Graduate School and Faculty of Medicine, Ethics Committee issued approval R2805. The study design was approved by the appropriate ethics review board. The requirement of written informed consent was waived. Instead, opt-out consent documents were shown on the website of Kyoto University for patients who did not wish to participate in the study. Conflicts of interest: In compliance with the ICMJE uniform disclosure form, all authors declare the following: Payment/services info: All authors have declared that no financial support was received from any organization for the submitted work. Financial relationships: All authors have declared that they have no financial relationships at present or within the previous three years with any organizations that might have an interest in the submitted work. Other relationships: All authors have declared that there are no other relationships or activities that could appear to have influenced the submitted work.

\section{Acknowledgements}

We thank Dr. Yuji Kitada and Dr. Fumihiko Kuwata at Kyoto University for their clinical supports.

\section{References}

1. Hackman T, Rickert CG, Getz AE, Uppaluri R: Endoscopic surgical management of vidian nerve schwannoma. Laryngoscope. 2011, 121:241-244. 10.1002/lary.21285

2. Kassam $A B$, Vescan $A D$, Carrau RL, et al.: Expanded endonasal approach: vidian canal as a landmark to the petrous internal carotid artery. J Neurosurg. 2008, 108:177-183. 10.3171/JNS/2008/108/01/0177

3. Fortes B, Beer-Furlan A, Balsalobre L, Vellutini E, Stamm A: Endoscopic endonasal access for the treatment of Vidian nerve schwannoma: a case report. Braz J Otorhinolaryngol. 2019, 85:670-672. 10.1016/j.bjorl.2016.04.015

4. Suzuki M, Nakamura Y, Nakayama M, Inagaki A, Murakami S, Takemura K, Yokota M: Modified transnasal endoscopic medial maxillectomy with medial shift of preserved inferior turbinate and nasolacrimal duct. Laryngoscope. 2011, 121:2399-2401. 10.1002/lary.22326

5. Cheong JH, Kim JM, Bak KH, Kim CH, Oh YH, Park DW: Bilateral vidian nerve schwannomas associated with facial palsy: case report and review of the literature. J Neurosurg. 2006, 104:835-839. 10.3171/jns.2006.104.5.835

6. Honda K, Asato R, Tanaka S, Endo T, Nishimura K, Ito J: Vidian nerve schwannoma with middle cranial fossa extension resected via a maxillary swing approach. Head Neck. 2008, 30:1389-1393. 10.1002/hed.20793

7. Wu SW, Chen WL, Chen WL, Chen MK: Transnasal endoscopic resection of vidian nerve schwannoma accompanied by sphenoid mucopyocele and oculomotor palsy: a case report. B-ENT. 2012, 8:207-211.

8. Hong HP, Yoon SW, Park MJ, Jung SC: A case of vidian nerve schwannoma: resection by endoscopic sinus surgery. Korean J Otorhinolaryngol-Head Neck Surg. 2014, 57:50-53. 10.3342/kjorl-hns.2014.57.1.50

9. Yamasaki A, Sedaghat AR, Lin GC, Curry WT, Shih HA, Gray ST: A rare finding of schwannoma of the vidian canal: a case report. J Neurol Surg Rep. 2015, 76:48-51. 10.1055/s-0034-1544112

10. Masroor FA, Gilde J, Liang J: Vidian nerve schwannoma: a rare skull-base neoplasm presenting with ocular manifestations: a case report and literature review. Perm J. 2018, 22:18-21. 10.7812/TPP/18-021

11. Xie Y, Yang Q, Xie G, Pang J, Fan Z, Li D: Improved black-blood imaging using DANTE-SPACE for simultaneous carotid and intracranial vessel wall evaluation. Magn Reson Med. 2016, 75:2286-2294. 


\section{Cureus}

$10.1002 / \mathrm{mrm} .25785$

12. Niepel AL, Steinkellner L, Sokullu F, Hellekes D, Kömürcü F: Long-term follow-up of intracapsular schwannoma excision. Ann Plast Surg. 2019, 82:296-298. 10.1097/SAP.0000000000001812 